\title{
A study of a respiratory related variation of muscle tone during the decrement of decerebrate tonicity in ECT
}

\author{
P. C. C. TRESISE \\ From the Royal Perth Hospital, W. Australia
}

SUMMARY An oscillating decerebrate tonicity following the clonus phase in electroplexy was found to occur in the upper limbs, their tendon reflexes and the jaw; this increased with each expiration and decreased with inspiration. The times of these occurrences in the upper limbs were measured in groups where no anaesthesia, diazepam or methohexital were used. The mean times of their onset and end were related to other phenomena of ECT. The times of occurrence and duration of decerebrate tonicity were established and compared in the three cohorts. There was a definite relationship to the onset of respiratory rhythmicity in all three groups. The evidence for the existence of decerebrate tonicity and atonicity are discussed from experimental contributions and more recent clinical evidence of the clonus phase as an example of an oscillation between tonic and atonic decerebrate states. Further clinical and experimental data are discussed which show connections between the decerebrate state, cerebral and cerebellar functions, respiratory centres, brain-stem and gravity afferents during rest and locomotion. An explanation is offered that the oscillatory phenomena are probably a mechanism to aid respiration and motor efficiency.

A study to help determine the normal movement in ECT phases showed an oscillating tonus state in the upper limbs. Awareness of this permitted more definite timing of the decerebrate tonicity in the upper limbs coinciding with each inspiration and an increase with each subsequent expiration.

The times of occurrence of these and other phenomena were measured from three populations of records of electroconvulsive therapy (ECT) given with methohexital (Brietal), diazepam (Valium), or with no adjuvant anaesthesia.

METHOD

The patients studied were all suffering from depressive disorders without neurological disease. They were prepared and given ECT in the routine manner (Tresise and Stenhouse, 1968a, b). Preoperative diazepam was given in some and methohexital in others, to obtain patient cooperation and somnolence but not anaesthesia. Hypnotherapy was administered when no anaesthetic was used.

A microphone above the patient's head was connected to an audiotape, which recorded both the respiratory stages and the author's clinical signals; a clock similarly placed allowed the ECT events to be timed.

Variation of the flexor tone during inspiration and expiration was bilaterally palpable by sudden and slow passive hyperflexion and return of the forearms to their flexed decerebrate position. A positive or negative resistance felt on the return movement was verbally recorded via the microphone. Patients who showed an absence of the decerebrate tonicity in either upper or lower limbs were excluded from the study.

It was frequently sensed through holding the operator's thumb on and beneath the lower teeth-to control the jaw and airway - that there was a variation of tonicity in the jaw during the return of respiratory rhythmicity. One instance is shown where an electroplectograph was used to record the variations of muscle tone in the jaw to demonstrate a respiratory relationship. This instrument consisted of a flexible water-filled pad held in the mouth, connected by pressure tubing to a marking stylus pen which traced the pressure changes on moving paper. Signals to the graph on each respiration were made by independent observers (see Fig. 2).

The tendon reflexes of the brachial biceps, femoral quadriceps, and soleus muscles were tested before and after anaesthesia, during the post clonus and recovery stages. The frequency of the tendon taps varied from 1 to 
3 per second. There was an increase of the reflex response in the biceps muscle during expiration. No clinical variation in the lower limbs was demonstrable. Because of the transient nature of the phenomenon, measured times assessed by passive palpation were used in this study.

\section{RESULTS}

The tendon reflexes were found most often to be depressed with diazepam and methohexital compared with no anaesthesia. They were symmetrically exaggerated during the decerebrate tonicity stage and continued to be so after this tonicity had palpably disappeared in all limbs. The patellar reflexes were more frequently less active compared with the biceps and ankle jerks.

The biceps reflex and its flexor tone were also found to be increased during the decrement of the decerebrate tonicity on expiration and depressed on inspiration. There was no palpable extensor tone in the forelimbs at this stage, thus making the changes in decerebrate flexion tone more discernible.

Figure 1 shows a total of 537 treatments-39 with diazepam, 93 without anaesthesia, and 405 with methohexital. Of these, 10 with diazepam, 24 without anaesthesia, and 43 with methohexital were measured with the lessening of forearm flexor tone on inspiration and increase on expiration. The mean times $(\mathrm{sec})$ of their onset are marked with vertical hatching and labelled 'oscillatory tone begins', as shown in the legend, and placed beneath the mean times of onset of respiration and its rhythmicity in each of the cohort studies.

The mean times of onset and end of the decerebrate tone in the upper limbs are set immediately

\section{TIME FLOW (in seconds) FROM STIMULUS ONSET AT ZERO}

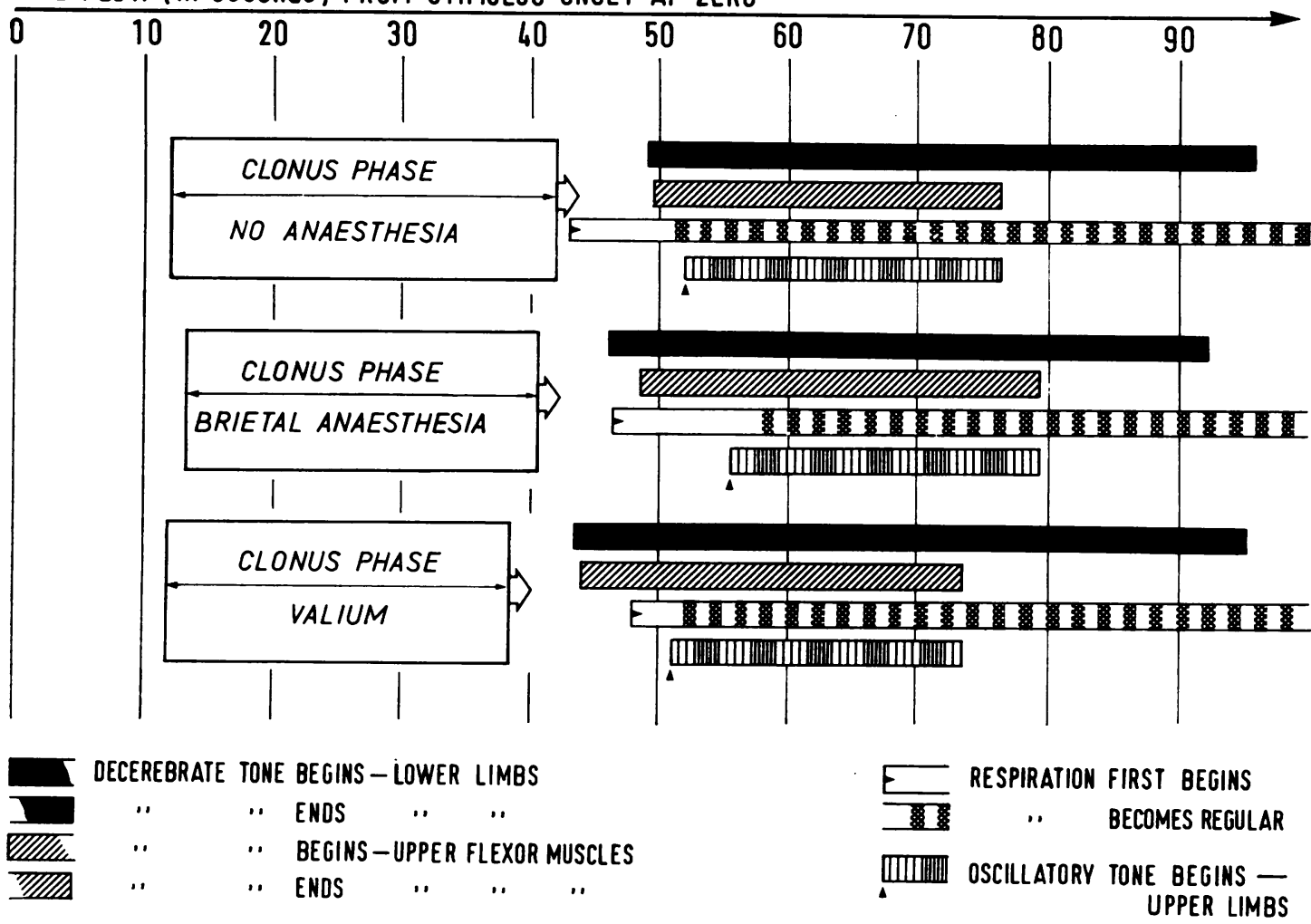

FIG. 1. Studies of the ECT phases without anaesthesia (93), methohexital anaesthesia (405), and diazepam (39) are placed above each other. The means of their times of onset and end of clonus are blocked in along the ECT time flow. The key indicates the mean times of onset and end of the decebrate tonicity in the upper and lower limbs, the beginning of respiration and its rhythmicity, the beginning of the oscillatory phenomenon and its cessation with the ending of the decerebrate tonicity in the upper limb. The mean values are taken from the statistical data in the Table. 
above those of the respiration and beneath the times of the decerebrate occurrences of the lower limbs. Mean times of onset and end of clonus are named and blocked in, with an arrow at the end times pointing in the direction towards the subsequent ECT events. Comparison of the cohorts shows the respiratory onset and its rhythmicity to be earliest without anaesthesia, and it is noteworthy that the onset of decerebrate tonicity in the upper and lower limbs is earliest with diazepam and this graph has the shortest duration of oscillatory phenomenon.

It is of interest that subsiding decerebrate tonicity in the upper limbs and onset of the oscillatory phenomenon are much more related to the actual return of the respiration rhythmicity than other measured values of the ECT events. Methohexital, however, being one of the least depressant barbiturates, still shows a relatively delayed recovery of respiratory rhythmicity which is peculiar to barbiturates in general.

The Table shows the statistical data from which the graph of Fig. 1 is drawn. The age, sex, stimulus, and anaesthetic dose as determining variables, have not been included, as such statistical studies require a separate publication.

Figure 2 shows a jaw tracing from an electroplectogram. The jaw closes with the initial electrical dose as shown by the upward vertical swing and then returns to the relaxed base line for two seconds. This is marked by a small black horizontal line to illustrate the interval. After this, the jaw lead rises as the mouth closes in the tonus phase. The continuing straight line represents a constant tone until clonus begins. After the clonus spasms cease, the jaw pressure relaxes and the trace returns to the horizontal line. The jaw tone rises again at the point marked 'Respiratory masseter reflex'. The four vertical lines are made by joining the times of each recorded respiration. There is an oscillating rise and fall of the jaw with each respiratory phase. This is a similar kind of variation to the biceps reflex and
TABLE

STATISTICS RELATING TO FIG. 1

\begin{tabular}{|c|c|c|c|c|c|c|}
\hline & \multicolumn{2}{|c|}{$\begin{array}{c}\text { Diazepam } \\
\text { (39) }\end{array}$} & \multicolumn{2}{|c|}{$\begin{array}{c}\text { No } \\
\text { anaesthesia } \\
\text { (93) }\end{array}$} & \multicolumn{2}{|c|}{$\begin{array}{c}\text { Methohexital } \\
\text { (405) }\end{array}$} \\
\hline & $\begin{array}{c}\text { Mean } \\
(\mathrm{sec})\end{array}$ & $S D$ & $\begin{array}{c}\text { Mean } \\
(\mathrm{sec})\end{array}$ & $S D$ & $\begin{array}{c}\text { Mean } \\
\text { (sec) }\end{array}$ & $S D$ \\
\hline Clonus begins & $11 \cdot 9$ & $4 \cdot 84$ & $12 \cdot 1$ & $5 \cdot 42$ & $14 \cdot 4$ & 8.01 \\
\hline Clonus ends & $38 \cdot 4$ & $7 \cdot 59$ & $42 \cdot 1$ & $9 \cdot 46$ & $41 \cdot 1$ & 8.67 \\
\hline Respiration begins & $47 \cdot 3$ & 1055 & 43.9 & $10 \cdot 79$ & $46 \cdot 8$ & $10 \cdot 11$ \\
\hline $\begin{array}{l}\text { Respiration regular } \\
\text { Decerebrate tone begins }\end{array}$ & $52 \cdot 2$ & $13 \cdot 56$ & $51 \cdot 2$ & $13 \cdot 73$ & $58 \cdot 0$ & $12 \cdot 51$ \\
\hline Lower limb & $43 \cdot 7$ & $7 \cdot 91$ & $48 \cdot 6$ & $10 \cdot 73$ & $46 \cdot 6$ & $10 \cdot 38$ \\
\hline Upper limb & $44 \cdot 3$ & $7 \cdot 87$ & $49 \cdot 2$ & $10 \cdot 83$ & $48 \cdot 4$ & $9 \cdot 75$ \\
\hline \multicolumn{7}{|l|}{ Decerebrate tone ends } \\
\hline Upper limb & $73 \cdot 1$ & 19.96 & 76.4 & $17 \cdot 00$ & $79 \cdot 8$ & $17 \cdot 00$ \\
\hline Lower limb & $95 \cdot 9$ & $34 \cdot 17$ & $96 \cdot 0$ & $29 \cdot 38$ & $94 \cdot 2$ & $23 \cdot 38$ \\
\hline \multicolumn{7}{|l|}{ Oscillatory phenomenon } \\
\hline Total numbers & (10) & & (24) & & (43) & \\
\hline Begins & $51 \cdot 6$ & $7 \cdot 3$ & 53.7 & $10 \cdot 75$ & $55 \cdot 8$ & $10 \cdot 75$ \\
\hline Ends & $\begin{array}{l}\text { At the } \\
\text { in th }\end{array}$ & time o & $f$ endin & $g$ of de & cerebra & te tone \\
\hline
\end{tabular}

its decerebrate tone. Clinically, the jaw variation is present or absent according to the individual, age and degree of dentition.

\section{DISCUSSION}

This study adds to knowledge of alternating oscillating, and reciprocal systems-the characteristic properties of nervous function and the basis of neural rhythmicity. Locomotion, sleep, memory, and the maintenance of life would be impossible without these reversible systems and their mechanisms. Electroplexic therapy (ECT) influences all the above systems and functions, producing a beneficial reversibility of the depressive disease. The term electroplexic therapy is preferred because it evokes the need to know where the electrical dose goes, what physiological changes it brings about, and why

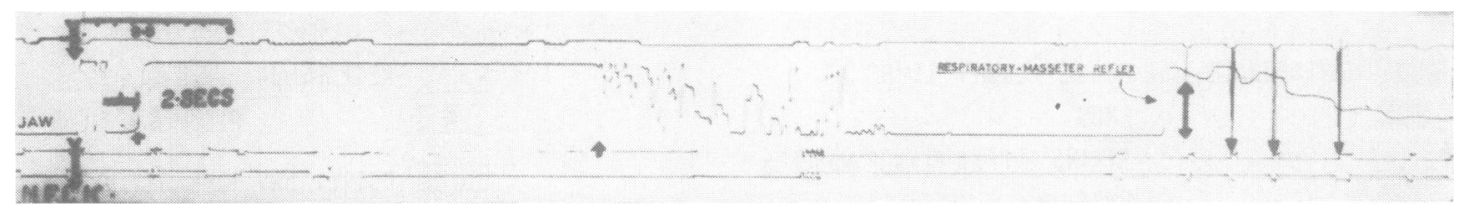

FIG. 2. A tracing from the jaw during an electroplectic treatment displays the changes of the muscle tension of the jaw muscles. The stimulus was given at the first arrow. The stimulus response follows, then a 2 sec interval during which the mouth was opened during the respiratory 'cry' in the kinetic phase. The rise of jaw tension follows in the tonus phase, then the spasms of the clonus phase; after this there is little jaw tension until it rises again with the return of respiration, as indicated by the four vertical lines. This helps to show a time relationship between the waning jaw tension and return of respiratory rhythmicity. 
it gives benefit. The present evidence indicates some relationship between a reversible tonicity and atonicity in the flexor tone in biceps brachialis, abdominal muscles, and jaw during the last recurring state of decerebrate tonicity in the post-clonus stage, with a reciprocating inspiration-expiration phenomenon.

Mechanisms for the tonic and atonic decerebrate postural state or reflex are mainly in the area encompassing the hypothalamus-cerebellum-ponsmedulla which incorporates the respiratory centre. Sherrington (1898) demonstrated that experimental decerebrate rigidity was reversed into a flaccid state by spinal, cerebellar, pyramidal, cutaneous, and peripheral stimulations. Keller (1945) showed that the decerebrate state oscillated between rigidity and flaccidity. His preparations with mid-pontine lesions were flaccid when quiescent but regained muscle tone on arousal. Hodes and Suzuki (1965) showed that in preparations with brain-stem lesions there were fluctuations in forelimb muscle tone during inspiration and expiration in both wakefulness and sleep. It is apparent that there are different mechanisms determining the function of the fore and hindlimb. The author has never been able to observe respiratory oscillations of tone in the lower limbs during this stage of ECT.

Corda, von Euler, and Lennerstrand (1966) showed a relationship between the cerebellum and respiration. They demonstrated that alpha and gamma activity in the intercostal nerves were facilitated with contralateral, and inhibited with ipsilateral stimulation of the cerebellum. This strongly suggests that cerebellation or memory of muscle activities is linked with the respiratory function. Robson, Housely, and Solis-Quiroga (1963) showed the respiratory centre to have an absolute bistable function biased towards inspiration rather than expiration. It is noteworthy that inspiration in this study shows a similar bias with depression of muscle tone and reflex excitability. Respiration has other alternating mechanisms associated with the functions of sleep, rest, arousal, and movement. Glebovski (1966) showed that the control of respiration had dependent relationships with the stretch mechanisms of the intercostal muscles and thoracic volume. Johnson and Luckardt (1928) showed that the knee jerks were depressed when the intrapulmonary pressure is raised. Schweitzer and Samson Wright (1937) showed that spontaneous movements were inhibited in anaesthetized animals when the blood pressure was raised in an isolated carotid sinus. Strughold (1928) showed in cats and dogs under the influence of barbital narcosis that a variation in the knee jerk occurred on inspiration, as well as in normal humans. (In
Fig. 1 the biceps oscillatory tonicity is shown to occur with and without barbital. This indicates also that the phenomenon is not barbital dependent.)

The brachial and abdominal muscles act as flexors and in a functional sense are accessory respiratory muscles. Masserman (1937) inferred a link between locomotion, respiration, and the oscillatory biceps tonicity. He reported '. . . initial hypertensive effect of hypothalmic stimulation ... seemed to be correlated with the degree of coincident ske'etal muscular spasm, especially the abdomen...'Mental alertness arouses the neuromotor mechanisms for movement. Efficient locomotion is dependent upon properly functioning reciprocity of the flexionextension and tonicity-atonicity mechanisms. Keller (1945) displayed a connection between jaw movements, foodseeking, and limb actions. His experimental animals with low pontine transections ... usually elicited rhythmic movements in all limbs' when the mouth was opened widely.

Experimental decerebrate rigidity is well documented in literature as one form of transient postural reflex necessary for locomotion. The decerebrate tonic position of semiflexed upper limbs and extended lower limbs was shown by Ward (1947) to emerge in a transient way in sodium cyanide intoxication. Clinically, Denny-Brown (1960, p. 1104) describes its emergence as a neurological sign of striatal lesions as the Foerster syndrome. Conomy and Swash (1968) reported a reversible toxic decerebrate state. Tresise and Stenhouse $(1968 \mathrm{a}, \mathrm{b})$ reported that the decerebrate tonicity recurrently re-emerged throughout the electroplexic phases. The present work shows an oscillating tonicity and atonicity in the upper limbs to be related to respiration and a decerebrate state after the ECT clonus phase. How and why this is linked is unclear.

The work of Martin (1963) can help clarify some answers. He combined the decerebrate position, respiration, gravity, and motion non-specifically to help his Parkinsonism patients regain walking habits. Patients were advised to carry a chair with their forearms flexed in the decerebrate position to improve their disabled powers of locomotion. His empirical application of the decerebrate position, when examined further, may help explain the phenomenon of oscillating biceps tonicity of this study. He states that the stepping, falling, gliding, and rocking mechanisms required for locomotion cannot be produced by neural stimulation. The combination of the decerebrate position of flexed upper limbs, additional stimuli from gravity and muscle spindle receptors facilitate the stepping and propulsion mechanisms. Standing man elevates the rib cage against gravity and relaxes the abdominal muscles in order to inspire. To expire passively, the 
chest muscles become relaxed and the rib cage falls with the help of gravity and lung elasticity. The abdominal muscles remain relaxed. Running man requires additional respiratory aeration and locomotor mechanisms. The spinal and chest axis changes from the vertical towards one of $45^{\circ}$. The propulsive falling mechanism is enhanced. Expiration is improved with the forearms flexing into the decerebrate position to aid the accessory chest and abdominal muscles. A reciprocating tangential thrust of the upper flexed limbs reinforces other propulsive mechanisms. It is postulated that these kinds of neuromotor mechanisms are returning at this stage in ECT as a natural sequence and to assist the reintegration of the metabolic and respiratory needs; the oscillating phenomenon is also a part of this recovery process.

The help of the following is gratefully acknowledged: Mr. and Mrs. R. Robinson (electrical and secretarial assistance); the psychiatric staff of Royal Perth Hospital and St. John of God Hospital; Mr. Van Raalte, Medical Illustrations Department, Royal Perth Hospital; The Raine Trust and the associated staff of Department of Medical Statistics, University of Western Australia; and Miss Gillett, Medical Library Department, Royal Perth Hospital.

\section{REFERENCES}

Conomy, J. P., and Swash, M. (1968). Reversible decerebrate and decorticate postures in hepatic coma. New Engl. J. Med., 278, 876-879.

Corda, M., von Euler, C., and Lennerstrand, G. (1966). Reflex and cerebellar influences on $\alpha$ and on 'rhythmic' and 'tonic' $\gamma$-activity in the intercostal muscle. J. Physiol. (Lond.), 184, 898-923.

Denny-Brown, D. (1960). Diseases of the basal ganglia. Their relation to disorders of movement. I and II. Lancet, ii: 1099-1105; ii, 1155-1163.

Glebovskii, V. D. (1966). Stretch reflexes of intercostal muscles. Fed. Proc., Translation Suppl., 25, T.937-T.942.

Hodes, R., and Suzuki, J. I. (1965). Comparative thresholds of cortex, vestibular system and reticular formation in wakefulness, sleep and rapid eye movement periods. Electroenceph. clin. Neurophysiol., 18, 239-248.

Johnson, C. A., and Luckhardt, A. B. (1928). Studies of the knee jerk: effect of raised intrapulmonic pressure upon knee jerk, arterial blood pressure and state of consciousness. Amer. J. Physiol., 83, 642-652.

Keller, A. D. (1945). Generalised atonia and profound dysreflexia following transection of the brain stem through the cephalic pons. J. Neurophysiol., 8, 275-288.

Martin, J. P. (1963). The basal ganglia and locomotion. Ann. roy. Coll. Surg. Eng., 32, 219-239.

Masserman, J. H. (1937). Effects of sodium amytal and other drugs on the reactivity of the hypothalmus of the cat. Arch Neurol. Psychiat. (Chic.), 37, 617-628.

Robson, J. G., Houseley, M. A., and Solis-Quiroga, O. H. (1963). The mechanism of respiratory arrest with sodium pentobarbital and sodium thiopental. Ann. N.Y. Acad. Sci., 109, 495-504.

Schweitzer, A., and Samson Wright (1937). Effects on the knee jerk of stimulation of the central end of the vagus and various changes in the circulation and respiration. $J$. Physiol. (Lond.), 88, 459-475.

Sherrington, C. S. (1898). Decerebrate rigidity and reflex $\mathbb{D}$ coordination of movements. J. Physiol. (Lond.), 22, @ 319-332.

Strughold, H. (1928). Die Reflexe, betrachtet nach ihrero funktionellen Bedeutung. Nervenarzt, I, 470-478.

Tresise, P. C., and Stenhouse, N. S. (1968a). A study of the clonus phase in ECT. Aust. N.Z. J. Psychiat., 2, 147-154.

Tresise, P. C., and Stenhouse, N. S. (1968b). ECT phases with and without anaesthesia: a preliminary statistical study. Brit. J. Psychiat., 114, 1383-1386.

Ward, A. A. (1947). Decerebrate rigidity. J. Neurophysiol., 10, 89-103. 